Article

\title{
Improvement of Equality in the Distribution of Human Resources in Polish Healthcare
}

\author{
Justyna Rój \\ The Poznań University of Economics and Business; justyna.roj@ue.poznan.pl; Tel.: +48.856.90.00
}

\begin{abstract}
Human resources are the major input of health systems therefore the equitable distribution of human resources in health care remain critical in making progress towards the goal of universal health coverage and thus to sustainable development. The purpose of this study is to evaluate the health care human resources distribution across regions of Poland between 2010 and 2017 and estimate the level of equity. This research by applying to Polish conditions will allow to fill in the gap in existing literature. Data was derived from the Knowledge Database Health and Health Care of Statistic Poland and Polish Statistical Yearbook. In purpose to examine the distribution of health resources against population size and geographic size in Poland, the Gini coefficient calculated based on the Lorenz Curve was engaged. This study has several major findings. The amount of most types of human resources - as apart from internist, obstetrics and gynecology, occupational medicine - when expressed as number of them per 10,000 population or 1 square $\mathrm{km}$ increased in 2017 compared to 2010. Moreover, for most types of health care human resources the level of access slightly changed during analysied period as Gini coefficients decreased. However, the geographical distribution of all types of human resources is less equitable then in case of population distribution. The most troublesome is relatively lower equity in case of oncologist, family medicine and occupational medicine and cardiologist in both population and geographical distribution. Thus this research provides some implications for policy and practice. As the main reason to establish National Health Fund (which meant the centralization of the system) in Poland was to to eliminate regional differences in access to health care, thus this research confirms that still some more corrective actions, in this field, should be undertaken.
\end{abstract}

Keywords: health care, human resources, inequality, Gini coefficient.

\section{Introduction}

Good health is essential to sustained economic as well as to social development and also poverty reduction [1]. Health affects people's well-being as healthy children are better able to learn, then it influences their ability to work or pursue an education and at general the range of opportunities and life plans. So, health contributes to development and the overall well-being of society directly as well as indirectly through income and wealth [2]. Thus good health has impact on the quality of human capital while healthy population facilitates economic growth [3].

The crucial factor for maintaining and improving health is the access to needed health services with the protection being pushed into poverty because of the health care cost [1]. That's why introduction of universal health coverage has become a major goal of health care system reform in many countries as well as a priority objective of World Health Organization. Universal health coverage is defined: "as ensuring that all people have access to needed health services (including prevention, promotion, treatment, rehabilitation and palliation) of sufficient quality to be effective without being exposed to financial hardship in paying for the services" [2]. Thus it combines two key elements, the first relating to people's use of the health services they need and the second element relates to the economic consequences of doing so [4]. Even, the main motive of universal health coverage implementation is individual benefits from health service utilization as 
improvements in health but also by this widespread coverage, all society would benefit because it can improve population health [2].

As access to health services ensures healthier people, therefore, universal health coverage became a critical component of sustainable development and poverty reduction, and a key element to reducing social inequities [4]. There are some evidence provided by World Health Organization showing, that some countries improve health indicators and contribute to stronger economic development as well as reduce the poverty levels by increasing coverage with health services [5].

Thus, sustainability development requires an efficient health system that provides the entire population with access to good quality services, health workers, technologies and medicines [6,7].

As health systems are labour intensive, therefore human resources are treated as the most important of the health system's inputs among all three (with the other two major inputs being physical capital and consumables). In the context of health care, human resources are defined as the different kinds of both clinical and non-clinical staff who make each individual and public health intervention happen [8]. Also, in documents of World Health Organization, it is underlined that the health human capital will be crucial to achieve health and wider development objectives in the next decades [9].

Even, the health system would have plentiful human resources with excellent knowledge and skills, still could face impending crisis if there is inequitable access do them [10]. Equity matters as it refers to fair opportunity for everyone to attain their full health potential regardless of demographic, social, economic or geographic status. It entails the minimization of differences in access, coverage, quality, use and utility of health care between groups of the population categorized by above characteristics [11,12]. Therefore inequalities in access to health services leads to a low level of health [13]. Thus realization of the right to health must involve not only a concerted and sustained effort to improve health across all populations but also reduction of inequities in the enjoyment health. According to WHO, equity must be reached both between and within countries [11].

Therefore, the management of human resources plays a key role for the performance of health systems. However, it is a real challenge as health system must balance investments in human capital to cover future needs as well as present demands but also balance between the different types of health providers and also between health workers and physical resources [10].

Actually, many countries at all levels of socioeconomic development face, to varying degrees, difficulties in human resources management. Most of them suffer from the overall shortage of physicians, some with the problems with too many specialist and too few general practitioners. Also many are dealing with the problems by substituting among various health providers, it means with the reorientation of specialist physicians [10]. Moreover, many global health care system face the problem with the migration of health care workers. Such workforce mobility can create additional imbalances that require better work- force planning [9].

Because of the nature of health and health care, the health systems can only function with health workers. Thus improving health service coverage and realizing the right to the enjoyment of the highest attainable standard of health is dependent on human resources availability, accessibility, acceptability and quality. More availability of health human resources with the required competency is not sufficient, because they must be also equitably distributed and accessible by the population. Only then, this theoretical coverage can translate into effective service coverage. It is also underlined that "health priorities of the post-2015 agenda for sustainable development" - among others - "guaranteeing UHC - will remain aspirational unless accompanied by strategies involving transformational efforts on health workforce capability" $[9,14]$.

Also, the elimination of geographical and social inequalities in health is being one of the strategic objectives of the past and present National Health Programs in Poland [11]. The Republic of Poland is a country with the location in central and eastern Europe with both population of 38.1 million and area of $312685 \mathrm{~km} 2$ in 2018 [15]. It is also the largest country among the new Member States admitted to the EU after 2004. The Human Development Index for Poland was 0.865 in 2018. 
According to Article 68 of the 1997 Constitution of the Republic of Poland, all citizens, regardless of their financial status have the right to equal access, which should be ensured by the public authorities. Thus, the Polish Constitution of 1997 grants a general right to health care to every citizen as detailed conditions for as well as the scope of, the provision of services shall be established by statute. Moreover, special health care should be granted to children, pregnant women, handicapped people and persons of advanced age. In addition, public authorities are mandated to combat epidemics illnesses and prevent the negative health consequences of environmental degradation. They should also support the development of physical culture especially among children and adolescents [16]. Further, the system's legal framework is based on the 2004 Law on Health Care Services Financed from Public Sources [17], on the 2011 Law on Therapeutic Activity [18] and on legislation harmonizing Polish law with that of the EU [11].

The stewardship, management and financing functions in the Polish health care system are divided between the Ministry of Health, the National Health Funds (NHF) and territorial selfgovernments. Ministry of Health has progressively evolved from health care funder and organizer of health care provision to health policymaker and regulator. Mainly, the Ministry of Health has the overall responsibility for governance of the health sector and its organization. It is responsible for national health policy, implementation and coordination of health policy programs, major capital investments and also for medical research and education. The Ministry also has a number of supervisory functions. In addition, among others, it also regulates medical professions, jointly with the voivodeships evaluation of access to health care [11,19].

While, the major task of the NHF is to finance health services provided to the entitled population it also manages the process of contracting health services with public and non-public service providers (setting their value, volume and structure), monitors the fulfillment of contractual terms and is in charge of contract accounting. The quality and accessibility of health care services are to a certain extent influenced by the negotiated terms [19].

As Poland has three levels of territorial self-government, at each administrative level, territorial health authorities are responsible for the identification of the health needs of their respective populations, for planning of health services delivery, health promotion and the management of public health care institutions [11].

In Poland, the government's budget has historically been the main source of health care financing and a radical change of this system happened in 1999, while the implementation of market economy took place earlier, in 1989 [20]. Thus, in January 1999 - by introducing the 1997 General Health Insurance Act - a new general obligatory health insurance system entered into force, which changed the system of financing. with a system of financing from health contributions, based on social health insurance (SHI) rules. And as a result of this reform the purchaser and provider functions were split. It can be said that the decentralization of the system was placed [21]. A system of health insurance institutions, the so-called sickness funds (kasy chorych), was established. There were 16 sickness funds - one for each voivodeship - and a separate sickness fund for the uniformed services (members of the police, the military and the state rail) [22]. Because of the considerable differentiation of the number and quality of services in individual regions, this system was met with criticism from the new left-side government. However it potentially infringes the "equity" rule prescribed in the Constitution. So the new government adopted a different solution, instead of improving this system, they enforced a law on general insurance in the National Health Fund on April 1, 2003 [19].

Thus, sickness funds were replaced by a single central insurance institution - the National Health Fund. And the Head Office of the NFH and 16 regional branches, one in each voivodeship were established. It meant that the public funds for health care were again centralized. To eliminate regional differences in access to health care, the Law introduced uniform contracting procedures and point limits for contracted services [11]. However, shortly after - in January 2004, the law on universal insurance in the National Health Fund was legally qualified as not standing in accordance with the Constitution. As a result, the Sejm of the Republic of Poland passed the law on health 
benefits financed from public means on 30 July 2004, but the general idea of insurance in National Health Fund remained [23].

As, human resources are the major input of health systems and equity access do health care services has so high importance in the context of good health, which is then so important for the sustainable development, thus it is important to analyze the distribution of health care human resources - especially by area and population.

Because of importance of this topic and shortage of such research in the context of Poland, the purpose of this study is to evaluate the health care human resources distribution across regions of Poland between 2010 and 2017 and estimate the level of equity. There is no such structured studies in the context of Poland and this research will allow to fill in the gap in existing literature (there is some studies conducted from different context e.g. [24]). While this topic is widely analyzed in some other countries (e.g. [25-29]). To understand the trend of access to human resources in health care in Poland is important because it could be a base for the improving health policy. Moreover, the equitable distribution of human resources in health care remain critical in making progress towards the goal of universal health coverage and also to sustainable development.

\section{Materials and Methods}

Data related to health care human resources used in this study was derived from the Knowledge Database Health and Health Care of Statistic Poland [30] for the period from year 2010 to year 2017. As Poland is divided into 16 voivodeships, thus this study used, voivodeship - level data on health care human resources and each voivodeship was considered as a unit of analysis. The study data consisted of the number of physicians, number of nurses, number of dentist and number of pharmacist and number of all types of specialists. Moreover, data regarding to number of 16 different types specialists (which are more then $85 \%$ of specialist in general) were also collected. These numbers were then converted and expressed as number per 10,000 people and per square meter. Population and geographic area data was obtained from Polish Statistical Yearbook 2010-2017 [15]. Number of them were used as the indicators of health care resources in each region.

In purpose to exam the distribution of health resources against population size and geographic size in Poland, the Gini coefficient calculated based on the Lorenz Curve was engaged. Because it is recognized as one of the most common measure of distribution and also as one of the superior tool for measuring inequity [31,32].

The Gini coefficient was developed by the Italian Statistician Corrado Gini [33] as a summary measure of income inequality in society [34]. In this study, the Gini coefficient was calculated based on the Lorenz curve as a graphical representation [35,36]. The Gini coefficient is defined as the ratio where the numerator is the area between the Lorenz curve of the distribution and the uniform distribution line while the denominator is the area under the uniform distribution line. Thus the actual extent of inequality is presented by the area between Lorenz Curve and the line of perfect equality. It means, that more even distribution would be recognized in case of less deviation from the line of perfect equality.

The ratio can vary from 0 to 1 , where 0 corresponds to perfect human resources distribution (i.e. every units has this same resources per 10,000 people) and 1 means perfect human resources inequality (i.e. one has all the human resources, while everyone else has zero resources). Then Gini coefficient with the value less then 0.3 shows preferred equity status, then between $0.3-0.4$ means normal condition, while Gini coefficient with the value between 0.4-0.6 triggers an alert of inequity and the value exceeding 0.6 represents a highly inequitable state.

Two indicators were used for measuring inequity, reflecting the distribution of health care human resources among populations and the second among geographical location. And the following formula was used:

$$
\sum \mathrm{n}_{\mathrm{i}=1}(2 \mathrm{i}-\mathrm{n}-1) \mathrm{yi}
$$


(1)

$$
G(y)=\quad n^{2} y
$$

Where:

$\mathrm{y}_{\mathrm{i}}=$ value of i-observation

$\mathrm{n}=$ number of observations

\section{Results}

The results of this study showed that the number of physicians, dentist, nurse and pharmacist, expressed as per 10.000 population in Poland (table 1) has increased from the year 2010 to 2017. In case of pharmacist and physician, the change is above $10 \%$, it means $16.92 \%$ and $14.08 \%$ respectively. While number of dentist per 10.000 population has increased by $9.38 \%$ and the lowest change is reported in case of nurses, it means only $5.22 \%$.

Table 1. Health care human resources per 10,000 population in Poland in the years from 2010 to 2017

\begin{tabular}{ccccc}
\hline Year & physician & dentist & nurse & pharmacist \\
\hline 2010 & 20.6 & 3.2 & 47.9 & 6.5 \\
\hline 2011 & 20.9 & 3.3 & 48.4 & 6.8 \\
\hline 2012 & 22.1 & 3.2 & 54.9 & 7.0 \\
\hline 2013 & 22.1 & 3.2 & 52.1 & 7.1 \\
\hline \multirow{2}{*}{2014} & 22.7 & 3.4 & 51.7 & 7.2 \\
\hline 2015 & 23.0 & 3.3 & 51.4 & 7.3 \\
\hline 2016 & 23.9 & 3.5 & 51.0 & 7.6 \\
\hline 2017 & 23.5 & 3.5 & 50.4 & 7.6 \\
\hline change & $\mathbf{1 4 . 0 8 \%}$ & $\mathbf{9 . 3 8 \%}$ & $\mathbf{5 . 2 2} \%$ & $\mathbf{1 6 . 9 2 \%}$ \\
\hline
\end{tabular}

${ }^{1}$ Source: [30]

Analysis of number of all specialist (in general) and various type of specialists (totally 16 specialists which are more then $85 \%$ of specialist in general) presents variability in amount by which theses resources have been changed in 2017 compared to 2010.

Table 2. Health care specialists per 10,000 population in Poland in the years from 2010 to 2017

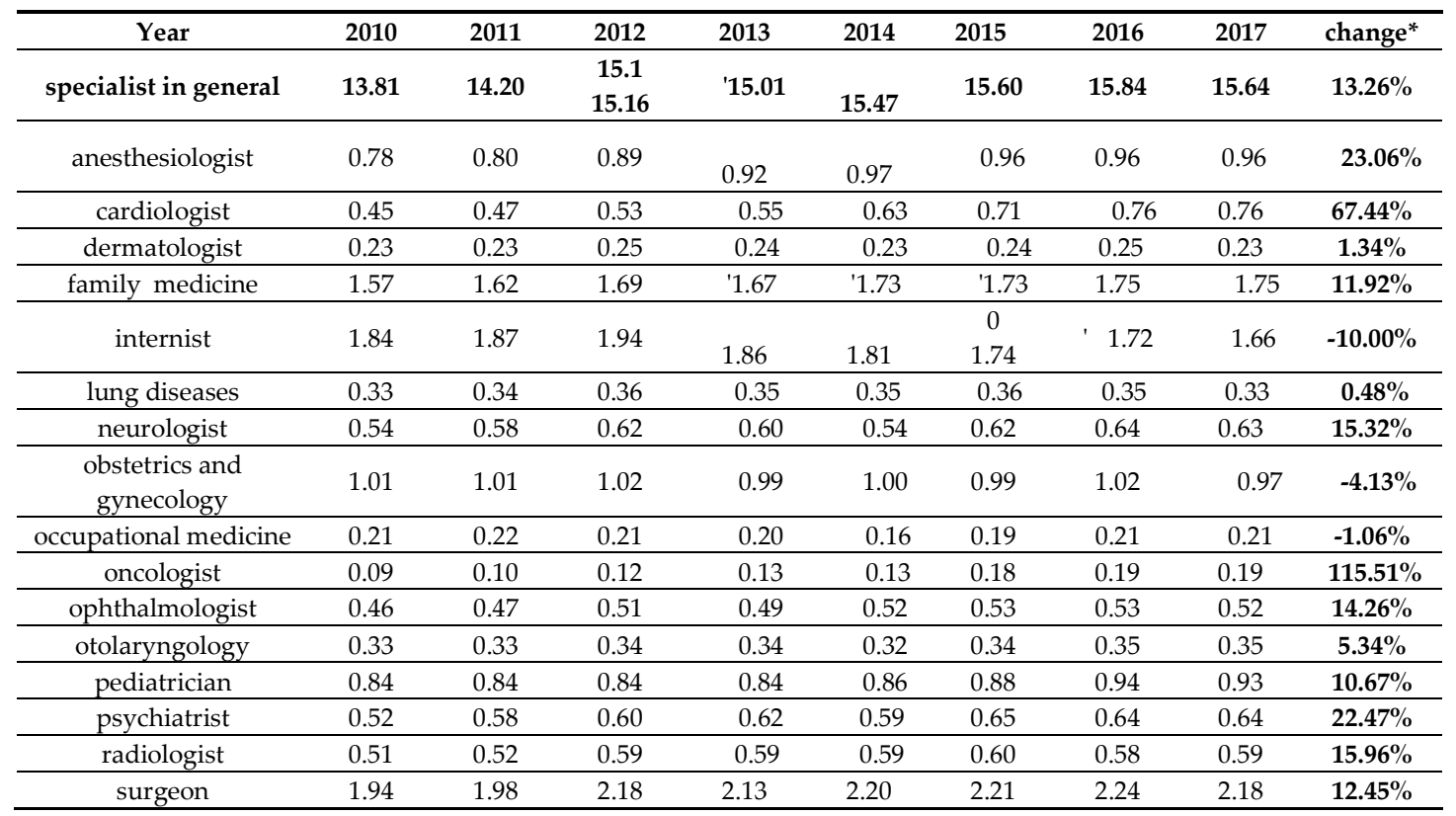


${ }^{1}$ Source: own calculation; the calculated change too into account more places (numbers) after the full-stop;

Generally, there is increase of specialists in general by $13.26 \%$. The most significant changed can be observed in case of oncologist $(115.51 \%)$ and cardiologist $(67.44 \%)$. Then there is a group of such specialists, which amount per 10.000 population has been changed by around $20 \%$ - it means anesthesiologist $(23.06 \%)$ and psychiatrist $(22.47 \%)$. The change of number of specialists per 10.000 population from 2010 compared to 2017 at the level ranged from 10.67\% to $15.96 \%$ (surgeon, family medicine, neurologist, ophthalmologist, pediatrician, radiologist). Smaller change occurred with reference to such specialists as lung diseases, dermatology, otolaryngology. While there is also decrease of number of such specialists: internist (by 10\%), obstetrics and gynecology (4.13\%) and occupational medicine $(1.06 \%)$.

Table 3. Health care human resources per 1 square $\mathrm{km}$ in Poland in the years from 2010 to 2017

\begin{tabular}{ccccc}
\hline Year & physician & dentist & nurse & pharmacist \\
\hline 2010 & 0.254 & 0.039 & 0.591 & 0.080 \\
\hline 2011 & 0.257 & 0.041 & 0.597 & 0.084 \\
\hline 2012 & 0.272 & 0.040 & 0.677 & 0.086 \\
\hline 2013 & 0.273 & 0.039 & 0.642 & 0.088 \\
\hline 2014 & 0.280 & 0.042 & 0.637 & 0.089 \\
\hline 2015 & 0.283 & 0.040 & 0.631 & 0.090 \\
\hline 2016 & 0.293 & 0.043 & 0.626 & 0.094 \\
\hline 2017 & 0.289 & 0.043 & 0.619 & 0.094 \\
\hline \multirow{2}{*}{ change } & $\mathbf{1 3 . 8 0 \%}$ & $\mathbf{8 . 1 5 \%}$ & & $\mathbf{1 6 . 7 6 \%}$ \\
\hline
\end{tabular}

1 Source: own calculation

Table 3 presents the number of physician, dentist, nurse and pharmacist respectively per 1 square $\mathrm{km}$, which has been increased from 2010 compared to 2017. Regarding to pharmacist and physician, the change is above $10 \%$, it means $16.76 \%$ and $13.80 \%$ respectively. While number of dentist per 10.000 population has increased by $8.15 \%$ and the lowest change is reported in case of nurses, it means only $4.85 \%$. While there is also decrease of number of such specialists per 1 square $\mathrm{km}$ : internist (by 9.37\%), obstetrics and gynecology (3.46\%) and occupational medicine (0.37\%).

Table 4. Health care specialties per 1 square $\mathrm{km}$ in Poland in the years from 2010 to 2017

\begin{tabular}{|c|c|c|c|c|c|c|c|c|c|}
\hline Year & 2010 & 2011 & 2012 & 2013 & 2014 & 2015 & 2016 & 2017 & change* \\
\hline specialist in general & 0.169 & 0.173 & $\begin{array}{c}0.00 \\
0.187 \\
\end{array}$ & 0.185 & 0.190 & 0.192 & $\begin{array}{c}0.19 \\
5 \\
\end{array}$ & 0.192 & $14.05 \%$ \\
\hline anesthesiologist & 0.010 & 0.010 & 0.011 & 0.011 & 0.012 & 0.012 & $\begin{array}{c}0.01 \\
2 \\
\end{array}$ & 0.012 & $23.92 \%$ \\
\hline cardiologist & 0.006 & 0.006 & 0.006 & 0.007 & 0.008 & 0.009 & $\begin{array}{c}0.00 \\
9 \\
\end{array}$ & 0.009 & $68.60 \%$ \\
\hline dermatologist & 0.003 & 0.003 & 0.003 & 0.003 & 0.003 & 0.003 & $\begin{array}{c}0.00 \\
3 \\
\end{array}$ & 0.003 & $2.04 \%$ \\
\hline family medicine & 0.019 & 0.020 & 0.021 & 0.021 & 0.021 & 0.021 & $\begin{array}{c}0.02 \\
2 \\
\end{array}$ & 0.022 & $12.70 \%$ \\
\hline internist & 0.022 & 0.023 & 0.024 & 0.023 & 0.022 & 0.021 & $\begin{array}{c}0 . \\
0.02 \\
1\end{array}$ & 0.020 & $-9.37 \%$ \\
\hline lung diseases & 0.004 & 0.004 & 0.004 & 0.004 & 0.004 & 0.004 & $\begin{array}{c}0.00 \\
4 \\
\end{array}$ & 0.004 & $1.18 \%$ \\
\hline neurologist & 0.007 & 0.007 & 0.008 & 0.007 & 0.007 & 0.008 & & 0.008 & 1 \\
\hline
\end{tabular}




\begin{tabular}{|c|c|c|c|c|c|c|c|c|c|}
\hline & & & & & & & $\begin{array}{c}0.00 \\
8\end{array}$ & & $16.12 \%$ \\
\hline $\begin{array}{l}\text { obstetrics and } \\
\text { gynecology }\end{array}$ & 0.012 & 0.012 & 0.013 & 0.012 & 0.012 & 0.012 & $\begin{array}{c}0.01 \\
3\end{array}$ & 0.012 & $3.46 \%$ \\
\hline occupational medicine & 0.003 & 0.003 & 0.003 & 0.002 & 0.002 & 0.002 & $\begin{array}{c}0.00 \\
3 \\
\end{array}$ & 0.003 & $\begin{array}{r}- \\
0.37 \%\end{array}$ \\
\hline oncologist & 0.001 & 0.001 & 0.002 & 0.002 & 0.002 & 0.002 & $\begin{array}{c}0.00 \\
2\end{array}$ & 0.002 & $117.01 \%$ \\
\hline ophthalmologist & 0.006 & 0.006 & 0.006 & 0.006 & 0.006 & 0.006 & $\begin{array}{c}0.00 \\
6\end{array}$ & 0.006 & $15.06 \%$ \\
\hline otolaryngology & 0.004 & 0.004 & 0.004 & 0.004 & 0.004 & 0.004 & $\begin{array}{c}0.00 \\
4\end{array}$ & 0.004 & $6.07 \%$ \\
\hline pediatrician & 0.010 & 0.010 & 0.010 & 0.010 & 0.011 & 0.011 & $\begin{array}{c}0.01 \\
2 \\
\end{array}$ & 0.011 & $11.44 \%$ \\
\hline psychiatrist & 0.006 & 0.007 & 0.007 & 0.008 & 0.007 & 0.008 & $\begin{array}{c}0.00 \\
8\end{array}$ & 0.008 & $23.33 \%$ \\
\hline radiologist & 0.006 & 0.006 & 0.007 & 0.007 & 0.007 & 0.007 & $\begin{array}{c}0.00 \\
7\end{array}$ & 0.007 & $16.77 \%$ \\
\hline surgeon & 0.024 & 0.024 & 0.027 & 0.026 & 0.027 & 0.027 & $\begin{array}{c}0.02 \\
8\end{array}$ & 0.027 & $13.23 \%$ \\
\hline
\end{tabular}

${ }^{1}$ Source: own calculation. ${ }^{*}$ the calculated change too into account more places (numbers) after the full-stop;

Analysis of number of specialist in general and various type of specialists (totally 16 specialists which are more then $85 \%$ of specialist in general) presents variability in amount by which those resources have been changed in 2017 compared to 2010, when expressed as number of particular specialist per 1 square $\mathrm{km}$ (table 4). Generally, there is increase of specialists in general by $14.05 \%$. Similar tendency of changes can be observed when expressing number of each types of specialists per 1 square $\mathrm{km}$. The most significant changed can be observed in case of oncologist $(117.01 \%)$ and cardiologist (by $68.60 \%$ ). Then there is a group of such specialists, which amount per 1 square $\mathrm{km}$. has been changed by around $20 \%$ - it means anesthesiologist $(23.92 \%)$ and psychiatrist $(23.33 \%)$. The change of number of specialists per 1 square $\mathrm{km}$ from 2010 compared to 2017 at the level ranged from $11.44 \%$ to $16.77 \%$ (surgeon, family medicine, neurologist, ophthalmologist, pediatrician, radiologist). Smaller change occurred with reference to such specialists as otolaryngology, lung diseases, dermatology.

From the analysis of Gini coefficients values it was noticed then the Gini coefficients against population size (table 5) ranged between 0.04 and 0.17 for the number of such human resources as physician, dentist, nurses and pharmacist, respectively indicating relatively good equality. What is also positive that slight improvement in the level of equality to access to three groups of health care workers is also recognized. For physician, the Gini coefficients has changed from the 0.08 (in 2010) to 0.06 (in 2017) and respectively for dentist from 0.16 (2010) to 0.14 (2017), then from 0.11 (2010) to 0.09 (2017) for the pharmacist. In case of nurses, the slight increased was noted from 0.06 (2010) to 0.07 (2017), which means the detoriation of equity level.

Table 5. Gini coefficients of population distribution of health resources in the years from 2010 to 2017

\begin{tabular}{ccccc}
\hline Year & physician & dentist & nurse & pharmacist \\
\hline 2010 & 0.08 & 0.16 & 0.06 & 0.11 \\
\hline 2011 & 0.08 & 0.17 & 0.06 & 0.10 \\
\hline
\end{tabular}




\begin{tabular}{lllcl}
\hline 2012 & 0.08 & 0.16 & 0.04 & 0.10 \\
\hline 2013 & 0.07 & 0.16 & 0.05 & 0.09 \\
\hline 2014 & 0.07 & 0.14 & 0.05 & 0.09 \\
\hline 2015 & 0.07 & 0.14 & 0.06 & 0.09 \\
\hline 2016 & 0.07 & 0.13 & 0.06 & 0.09 \\
\hline 2017 & 0.06 & 0.14 & 0.07 & 0.09 \\
\hline
\end{tabular}

${ }^{1}$ Source: own calculation

The Gini coefficients against geographic distribution (Table 6) of above health resources ranged between 0.25 and 0.32 indicating relatively good and normal equality. A slight improvement in the level of equality to access to nurse and pharmacist is also recognized, while there is no changes in the level of equity for the access to physician as the Gini coefficients for physician was in both 2010 and 2017 at the level of 0.3. The decrease in equity is noted in case of dentist as the Gini coefficients increased slightly from 0.26 in 2010 to 0.27 in 2017.

Table 6. Gini coefficients of geographic distribution of health resources in the years from 2010 to 2017

\begin{tabular}{ccccc}
\hline Year & physician & dentist & nurse & pharmacist \\
\hline 2010 & 0.30 & 0.26 & 0.30 & 0.32 \\
\hline 2011 & 0.30 & 0.27 & 0.30 & 0.32 \\
\hline 2012 & 0.30 & 0.27 & 0.28 & 0.32 \\
\hline 2013 & 0.29 & 0.26 & 0.28 & 0.31 \\
\hline 2014 & 0.29 & 0.25 & 0.29 & 0.32 \\
\hline 2015 & 0.30 & 0.29 & 0.29 & 0.31 \\
\hline 2016 & 0.30 & 0.29 & 0.29 & 0.31 \\
\hline 2017 & 0.30 & 0.27 & 0.29 & 0.30 \\
\hline
\end{tabular}

${ }^{1}$ Source: own calculation

In case of specialists in general and specialists in various fields of medicine, the Gini coefficients against population size ranged between 0.05 and 0.27 , which indicating relatively good equality (Table 7). Relatively, the most equitable access can be observed in case of specialists in general (0.06-0.08) and three more type of specialists as: to surgeon (0.05-0.06), anesthesiologist (0.06-0.08) and obstetrics and gynecology (0.08-0.09). Table 7 presents, that the less equitable access is in case of oncologist (0.15-0.27), family medicine (0.18-0.22) and occupational medicine (0.18-0.24).

Then a slight improvement - within the analyzed period - in the level of equality to access to specialist in general (0.29) has been observed as well as to seven types of specialist as for: family medicine, lung disease, occupational medicine, ophthalmologist, psychiatric, radiologist and relatively higher improvement in case of oncologist $(0.25$ to 0.16$)$. There are five types of specialists for which, the increase of the Gini coefficients was noticed which means the decrease of equity to assess to them (cardiologist, internist, obstetrics and gynecology otolaryngology and surgeon). There are also 4 types of specialists (anesthesiologist, dermatologist, neurologist, pediatrician) with no changes in the level of Gini coefficients between year 2010 and year 2017 and thus in the equity level within analyzed period, however slight variation of Gini ratio during this period between 2010 and 2017 can be observed.

Table 7. Gini coefficients of population distribution of health care specialists in the years from 2010 to 2017

\begin{tabular}{ccccccccc}
\hline Year & $\mathbf{2 0 1 0}$ & $\mathbf{2 0 1 1}$ & $\mathbf{2 0 1 2}$ & $\mathbf{2 0 1 3}$ & $\mathbf{2 0 1 4}$ & $\mathbf{2 0 1 5}$ & $\mathbf{2 0 1 6}$ & $\mathbf{2 0 1 7}$ \\
\hline specialist in general & 0.07 & 0.08 & 0.07 & 0.07 & 0.07 & 0.07 & 0.07 & 0.06 \\
\hline anesthesiologist & 0.07 & 0.07 & 0.06 & & 0.07 & 0.07 & 0.06 & 0.07 \\
\hline
\end{tabular}




\begin{tabular}{|c|c|c|c|c|c|c|c|c|}
\hline & & & & 0.08 & & & & \\
\hline cardiologist & 0.15 & 0.15 & 0.14 & 0.21 & 0.15 & 0.14 & 0.15 & 0.18 \\
\hline dermatologist & 0.12 & 0.14 & 0.12 & 0.15 & 0.12 & 0.12 & 0.13 & 0.12 \\
\hline family medicine & 0.22 & 0.22 & 0.20 & 0.21 & 0.19 & 0.19 & 0.19 & 0.18 \\
\hline internist & 0.11 & 0.12 & 0.10 & 0.10 & 0.12 & 0.12 & 0.12 & 0.12 \\
\hline lung diseases & 0.14 & 0.11 & 0.11 & 0.10 & 0.08 & 0.07 & 0.08 & 0.08 \\
\hline neurologist & 0.10 & 0.11 & 0.11 & 0.11 & 0.10 & 0.10 & 0.10 & 0.10 \\
\hline $\begin{array}{c}\text { obstetrics and } \\
\text { gynecology }\end{array}$ & 0.08 & 0.09 & 0.08 & 0.09 & 0.08 & 0.08 & 0.09 & 0.09 \\
\hline $\begin{array}{c}\text { occupational } \\
\text { medicine }\end{array}$ & 0.19 & 0.22 & 0.22 & 0.24 & 0.23 & 0.20 & 0.21 & 0.18 \\
\hline oncologist & 0.25 & 0.27 & 0.23 & 0.19 & 0.21 & 0.19 & 0.15 & 0.16 \\
\hline ophthalmologist & 0.12 & 0.12 & 0.11 & 0.13 & 0.12 & 0.12 & 0.12 & 0.10 \\
\hline otolaryngology & 0.09 & 0.08 & 0.09 & 0.10 & 0.09 & 0.08 & 0.09 & 0.11 \\
\hline pediatrician & 0.10 & 0.08 & 0.09 & 0.10 & 0.09 & 0.09 & 0.10 & 0.10 \\
\hline psychiatrist & 0.14 & 0.13 & 0.13 & 0.12 & 0.12 & 0.12 & 0.12 & 0.09 \\
\hline radiologist & 0.15 & 0.15 & 0.15 & 0.11 & 0.13 & 0.13 & 0.13 & 0.11 \\
\hline surgeon & 0.05 & 0.05 & 0.05 & 0.06 & 0.06 & 0.06 & 0.06 & 0.06 \\
\hline
\end{tabular}

1 Source: own calculation

In case of specialists in general and specialists in various fields of medicine, the Gini coefficients against geographic distribution ranged between 0.25 and 0.43 (Table 8). Relatively, the most equitable access can be observed in case of specialists in general( $(0.29)$ then to surgeon (from 0.29 to 0.28$)$ and anesthesiologist (0.28-0.30) and obstetrics and gynecology (0.25-0.26).

Then a slight improvement in the level of equality to access can be observed in case of eight types of specialists as as for dermatologist, family medicine, internist, neurologist, occupational medicine, ophthalmologist, surgeon. Then in case oncologist, the change is higher as from 0.38 to 0.33 .

There are three types of specialists for which, the increase of the Gini coefficients was noticed which means the decrease of equity to access to them as for: anesthesiologist, obstetrics and gynecology, pediatrician. In case of 5 types of specialists and specialist in general, no changes in the level of Gini coefficients between year 2010 and year 2017 and thus in the equity level were recognized, as for cardiologist, lung diseases, otolaryngology, psychiatrist, radiologist, however slight variation of Gini ratio during this period between 2010 and 2017 can be observed.

Table 8. Gini coefficients of geographic distribution of health care specialists in the years from 2010 to 2017

\begin{tabular}{ccccccccc}
\hline Year & $\mathbf{2 0 1 0}$ & $\mathbf{2 0 1 1}$ & $\mathbf{2 0 1 2}$ & $\mathbf{2 0 1 3}$ & $\mathbf{2 0 1 4}$ & $\mathbf{2 0 1 5}$ & $\mathbf{2 0 1 6}$ & $\mathbf{2 0 1 7}$ \\
\hline specialist in general & 0.29 & 0.29 & 0.28 & 0.29 & 0.29 & 0.29 & 0.29 & 0.29 \\
\hline anesthesiologist & 0.29 & 0.30 & 0.29 & 0.29 & 0.30 & 0.29 & 0.28 & 0.30 \\
\hline cardiologist & 0.37 & 0.38 & 0.37 & 0.37 & 0.37 & 0.38 & 0.37 & 0.37 \\
\hline dermatologist & 0.27 & 0.29 & 0.26 & 0.28 & 0.27 & 0.27 & 0.25 & 0.26 \\
\hline family medicine & 0.39 & 0.42 & 0.41 & 0.43 & 0.43 & 0.40 & 0.38 & 0.37 \\
\hline internist & 0.37 & 0.37 & 0.35 & 0.35 & 0.36 & 0.36 & 0.36 & 0.35 \\
\hline lung diseases & 0.30 & 0.30 & 0.29 & 0.30 & 0.28 & 0.28 & 0.29 & \\
\hline
\end{tabular}




\begin{tabular}{ccccccccc}
\hline & & & & & & & & 0.30 \\
\hline neurologist & 0.32 & 0.32 & 0.32 & 0.31 & 0.32 & 0.32 & 0.31 & 0.31 \\
\hline $\begin{array}{c}\text { obstetrics and } \\
\text { gynecology }\end{array}$ & 0.25 & 0.26 & 0.27 & 0.26 & 0.26 & 0.26 & 0.26 & 0.26 \\
\hline $\begin{array}{c}\text { occupational } \\
\text { medicine }\end{array}$ & 0.38 & 0.39 & 0.39 & 0.41 & 0.41 & 0.38 & 0.37 & 0.36 \\
\hline oncologist & 0.38 & 0.42 & 0.39 & 0.36 & 0.38 & 0.38 & 0.35 & 0.33 \\
\hline ophthalmologist & 0.33 & 0.32 & 0.32 & 0.33 & 0.32 & 0.33 & 0.31 & 0.31 \\
\hline otolaryngology & 0.31 & 0.29 & 0.29 & 0.29 & 0.29 & 0.30 & 0.30 & 0.31 \\
\hline pediatrician & 0.30 & 0.30 & 0.30 & 0.31 & 0.32 & 0.31 & 0.31 & 0.32 \\
\hline psychiatrist & 0.31 & 0.32 & 0.31 & 0.30 & 0.30 & 0.31 & 0.31 & 0.31 \\
\hline radiologist & 0.32 & 0.32 & 0.32 & 0.31 & 0.32 & 0.31 & 0.32 & 0.32 \\
\hline surgeon & 0.29 & 0.29 & 0.28 & 0.28 & 0.28 & 0.28 & 0.28 & 0.28 \\
\hline
\end{tabular}

1 Source: own calculation

The results showed that the geographical distribution of specialists in general and specialists in various fields of medicine is less equitable then in case of population distribution. The Gini coefficients against geographical ranged between 0.25 and 0.43 . For 11 types of specialists the Gini coefficients accepted the value from the range above 0.30. (not only in 2017 but in most of the years of analysis) and three of them had also value of this ratios above 0.4 during the analyzed period.

\section{Discussion}

On basis of the Gini coefficient, this paper reports on a comparative analysis of some slight inequality of health care human resources distribution in Poland. This study has several major findings. Firstly, the amount of all types of human resources (physician, nurses, pharmacist, dentist and specialist in general) when expressed as number of them per 10,000 population increased in 2017 compared to 2010. Also, it was observed that number of most different types of analyzed specialist increased in the above period with the most significant increase of oncologist and cardiologist. However, in case of three out of sixteen specialties - in such as internist, obstetrics and gynecology and occupational medicine - the decrease of their amount per 10,000 population was observed.

Also, this same tendency was observed when analyzing number of the human resources per 1 square $\mathrm{km}$. It was noticed that generally number of all types of human resources and most of different types of analyzed specialist increased in the above period with the most significant increase of oncologist and cardiologist. However, in case of three out of sixteen specialties - in such as internist, obstetrics and gynecology and occupational medicine - the decrease of their amount was observed. Generally, there is increase of amount of health care human resources expressed in both by population and per square $\mathrm{km}$.

Secondly, population distribution of all main types of health care human resources is quite equitable as Gini coefficients for distribution by population were below 0.17 , while for different types of specialists it was below 0.27 during all years of analysis and in 2017 even below 0.14 and 0.18 respectively. Moreover, it was noticed that apart from nurses, cardiologist, internist, otolaryngology, obstetrics and gynecology, surgeon the decrease of Gini coefficients were observed which means the improvement of equity took place. The relatively most higher improvement was noticed in case of on oncologist.

However, geographical distribution of all main types of human resources is less equitable as Gini coefficients for distribution by geographical area were below 0.32 and in case of different types of specialists it was below 0.43 during all years of analysis while in 2017 even below 0.30 and 0.37 respectively. It means that the geographic distribution of health care resources including also different types of specialists in Poland exhibits a slight level of inequality. The positive is that apart from - dentist, anesthesiologist, obstetrics and gynecology, pediatrician, the decrease of the 
Gini ratios took place, which means the improvement of equity in the access to these human resources. The higher improvement was noticed again in case of oncologist.

The results showed that the geographical distribution of all types of human resources and and specialists in various fields of medicine is less equitable then in case of population distribution. It implies there is ready access to healthcare in all regions, whilst the coefficients by geographical area apparently indicate inequality, which means that the equality of Poland's demographically assessed distribution of health care resources is greater than that of its geographically measured distribution. It can be also found out in research conducted in other country (e.g. 27,29]). This could be the result of the sparsity of population. Probably, most of the Polish health care resources are distributed within the developed provinces, especially in large cities developing provinces, fewer health care resources are allocated. The problem, however, requires further analysis, which should be expanded by including for example the analysis of the availability based on actual consumption of health care services provided by the above human resources.

What is positive that in most types of health care human resources the level of access slightly changed during analyzed years. The most troublesome is relatively lower equity in case still of oncologist, family medicine and occupational medicine and cardiologist in both population as well as geographical distribution and internist when it is expressed by 1 square $\mathrm{km}$. This unequal redistribution - especially in case of some types of specialists lead to differences in the access to health care services.

Moreover, despite the increase in the number of oncologists and cardiologists expressed at both per 10,0000 population and per square $\mathrm{km}$, they still present relatively lower equity compering with others. Also, very disturbing is the fact of significant inequality of family medicine specialists.

Thus this research provides some implications for policy and practice. As the main reason to establish National Health Fund (which meant also the centralization of the system) in Poland was to to eliminate regional differences in access to health care, thus this research confirms that still some more corrective actions, in this field, should be undertaken. On the one hand, the findings also confirm the Polish government's effort and input in increasing and thus providence with better access to health care human resources but on the other hand progress has not been fast enough or deep enough - especially in case of some specialists. Thus this policy should be changed in a way to provide more equity in the access to some specialists.

The results show the need to correct the health policy conducted by Ministry of Health as well as contracting system conducted by National Funds of Health in Poland. So, because of shortage of specialist The Ministry of Health should retrieve the medical education policy as well as the aspect of medical professions regulations. In purpose to provide more equitable access to human resources in health care Poland, the Ministry of Health and National Health Funds should expand the supply of improve human resource management. Results of this research also confirms that some actions should be taken in purpose to meet standards required by updated health workforce 2030 requirements, to achieve universal coverage health and Sustainable Development Goals 2016-2030 [37].

\section{Conclusions}

This paper focuses on the equity to access to human resources in health care as health systems are labour intensive and therefore human resources are treated as the most important of the health system's inputs. Health care services are delivered by people, therefore effective human resources management is so important and regional disparities in the allocation of health resources might be a significant obstacle, preventing some population from accessing basic health care. Although the distribution of health care resources was more adequate for the population size with some little variation among types of human resources, a striking difference was found in terms of the distribution per area. Geographical imbalances need to be taken into consideration when formulating policy rather than simply increasing the number of health care resources. Then this study can be used as the basis for health systems planning to correct the unequal distribution of 
health care resources. This study analyzed certain group of human resources, types of them were restricted by the availability of data. Additional studies can be conducted and should incorporate other types of health care resources if they would be availably, including moreover technological, infrastructures and financing to identify the overall circumstance of health resources in Poland.

Funding: This research received no external funding.

Conflicts of Interest: The authors declare no conflict of interest.

\section{References}

1. Universal Health Coverage. Available online: https://www.who.int/healthsystems/universal_health_coverage/en/(accessed on 12/10/18)

2. Making fair choices on the path to universal health coverage. Final report of the WHO Consultative Group on Equity and Universal Health Coverage, World Health Organization 2014

3. Rój J. (2011), Znaczenie czynnika finansowego w rozwoju technologii medycznych w klinice uniwersyteckiej, Wydawnictwo UEP.

4. Healthsystems. Financing. Available online:

https://www.who.int/healthsystems/topics/financing/uhc_qa/en/(accessed on 12/10/18)

5. Arguing for Universal Health Coverage, World Health Organization 2013, Available online: https://apps.who.int/iris/handle/10665/204355. (accessed on 12/10/18)

6. Healthsystems. Available online: https://www.who.int/healthsystems/en/ - (accessed on 12/10/18);

7. A Universal Truth: No Health Without a Workforce. Third Global Forum on Human Resources for Health Report, WHO 2013. Available online: https://www.who.int/workforcealliance/knowledge/resources/hrhreport2013/en/ (accessed on 12/10/18)

8. Kabene, S.M., Orchard C., Howard J.M., Soriano, M.A., Leduc R., (2006) The importance of human resources management in health care: a global context, Human Resources for Health, 4:20, doi:10.1186/1478-4491-4-20

9. Global strategy on human resources for health: Workforce 2030, Available online: https:/www.who.int/hrh/resources/globstrathrh-2030/en/(accessed on 12/10/18);

10. The world health report 2000 - health systems: improving performance,. Available online: https://www.who.int/whr/2000/en/ (accessed on 12/10/18);

11. Health Systems in Transition Vol.13 No. 8 2011; Poland. Health system review.European Observatory on Health Systems and Policies. Available online: http://www.euro.who.int/_data/assets/pdf_file/0018/163053/e96443.pdf (accessed on 12/10/18);

12. WhiteheadM.,(2000) The concepts and principles of equity and health. Available online: http://salud.ciee.flacso.org.ar/flacso/optativas/equity and health.pdf. (accessed on 12/10/18);

13. Bem A. Ucieklak-Jeż P. Siedlecki R., (2016) The Spatial Differentiation of the Availability of Health Care in Polish Regions, Procedia - Social and Behavioral Sciences 220

14. Health workcforce requirements for universal health coverage and the sustainable development goals. Human Resources for Health Observer - Issue No.17, WHO 2016. Available online:

https://www.who.int/hrh/resources/health-observer17/en/ (accessed on 12/10/18)

15. Polish Statistical Yearbook. Statistics Poland. Available online: https://stat.gov.pl/obszarytematyczne/ludnosc/powierzchnia-i-ludnosc-w-przekroju-terytorialnym-w-2018-roku,7,15.html. (accessed on 12/10/18)

16. The Constitution of the Republic of Poland of $2^{\text {nd }}$ April, 1997, as published in Dziennik Ustaw No.78, item 483 .

17. Act of 27 August 2004 About Health Care Benefits Financed From Public Funds

18. Act of 1 July 2011 about Therapeutic Activity

19. Kuszewski K. , Gericke Ch. (2005)., Health systems In transitions Poland, WHO

20. Rój J., (2009), The Cost Efficiency of Hospitals in Poland in Zoe Boutsioli (ed),Themes on Health Care: Challenges and Future Actions, Athens: ATINER

21. Rój J., (2004), Relationship between Funding Mechanism and Service Effectiveness of Hospital. In:J. N. Yfantopoulos (ed), The economics of health reforms, Athens: ATINER 
22. Rój J. (2010), Productivity of university hospitals in Poland: A Malmquist-index approach, Ekonomika, Vol. 89, Iss.4

23. Rój J., (2016), Competition measurement of hospitals in Poland: the herfindahl-hirschman index approach, Ekonomika. Vol. 95 Iss. 1.

24. Bem A., Ucieklak-Jeż P., Siedlecki R., (2013), Effects of inequalities in access to health services in rural areas in Poland, Management theory and studies for rural business and infrastructure development, Vol. 35. No. 4.

25. Ahoobim O., Altman D., Garrett L., Hausman V.,Huang Y., (2012) The New Global Health Agenda Universal Health Coverage, the Council on Foreign Relation USA.

26. Dan Li., Zhongliang Zhou, Yafei Si, Yongjian Xu, Chi Shen, Yiyang Wang, Xiao Wang, (2018) Unequal distribution of health human resources in mainland China:what are the determinants from a comprehensive perspective?, International Journal for Equity in Health,

27. Oyunchimeg Erdenee O., Paramita S.A., Yamazaki Ch., Koyama H., (2017) Distribution of health care resources in Mongolia using the Gini coefficient, Human Resources for Health.

28. Pallikadavath S., Singh A., Ogollah R., Dean T., Stones W., (2013) Human resource inequalities at the base of India's public health care system, Health \& Place, Vol.23, p.26-32.

29. Sefiddashti S.E., Arab M., Ghazanfari S., Kazemi Z., Rezael S., Karyani A.K., (2016) Trends of geographic inequalities in the distribution of human resources in healthcare system: the case of Iran, Electron Physician, Vol.8 iss. 7.

30. Knowledge Database Health and Health Care of Statistic Poland. Statistics Poland, Available online: http://swaid.stat.gov.pl/ZdrowieOchronaZdrowia_dashboards/Raporty_predefiniowane/RAP_DBD ZDR_5.aspx (accessed on 12/10/18).

31. Druckman A, Jackson T. (2008) Measuring resource inequalities: the concepts and methodology for an area-based gini coefficient. Ecol Econ. 65:

32. Wagstaff A, Paci P. Van Doorslaer E., (1991) On the measurement of inequalities in health, Soc. Sci Med. 33

33. Gini C., (1955). Variabilita e mutabilita 1912 reprinted in Memorie di metodologica statistica (Ed.

Pizetti E, Salvemini, T). Rome: Libreria Eredi Virgilio Veschi.

34. Gini C., (2005) On the measurement of concentration and variability of characters, Metron International Journal of Statistics vol. LXIII, issue 1.

35. Zhang T., Xu, Y., Ren J.., Sun L., Liu Ch., (2017) Inequlity in the distribution of health resources and health services in China: hospitals versus primary care institutions., International Journal for Equity Health 16:42,

36. Jin J., Wang J., Ma X., Wang Y., Li R., (2015), Equality of Medical Health Resources - Iran Journal Public Health Vol.44, No 4.

37. Health workforce requirements for universal health coverage and the Sustainable Development Goals; Human Resources for Health Observer - Issue No. 17, Available online: https://www.who.int/hrh/resources/health-observer17/en/ (accessed on 12/10/18) 